\title{
Vlogs e o incentivo à formação de leitores
}

\author{
Vlogs and the incentive to the formation of readers
}

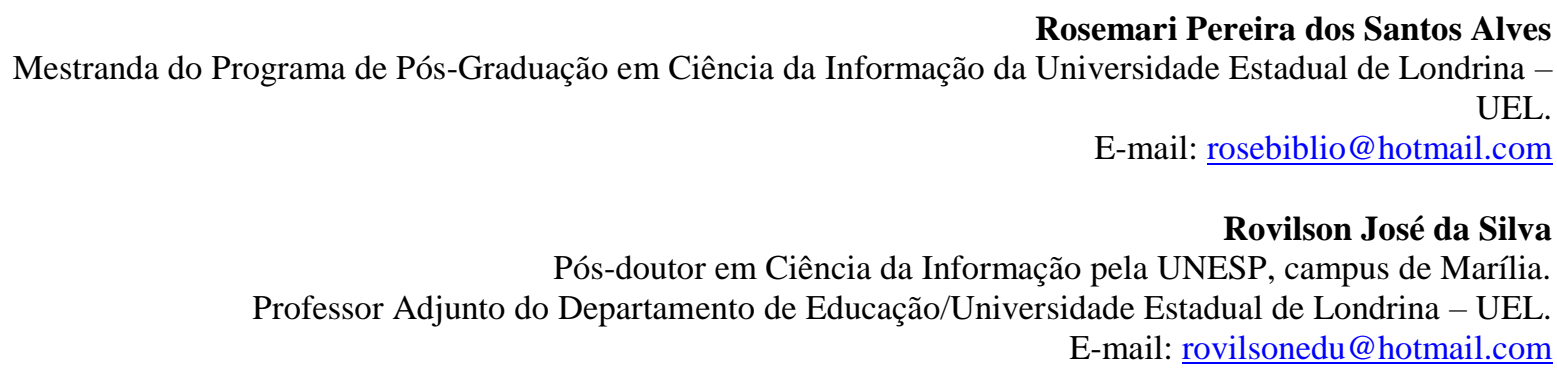

\section{Resumo}

Esta pesquisa, de natureza teórica, realiza uma breve retrospectiva histórica dos modos de leitura e, nesse contexto, destaca o movimento transmidiático, como tendência que o conteúdo on-line tem seguido, e os vlogs como importantes e democráticos veículos de comunicação da atualidade. Caracteriza o público alvo dos vlogs, que é constituído, predominantemente, por adolescentes que nasceram na era cibernética e não conseguem imaginar um mundo sem a convergência midiática e a internet. Defende a aplicação do vlog como instrumento de incentivo à literatura e apresenta propostas de utilização dele pela biblioteca escolar.

Palavras-chave: Modos de leitura. Vlogs. Mediação. Biblioteca escolar.

\begin{abstract}
This paper, of theoretical nature, presents a brief historic retrospective of the modes of reading and, in such context, highlights the transmedia, as a tendency followed by online content, and vlogs, as important and democratic veichles of communication. Characterizes the target audience of the vlogs, who are, predominantly, teenagers borned in the cybernetic age who cannot fathom a worl devoid of media convergence and internet. Defends the use of vlogs as incentive to literature and presents propositions of how this instrument can be used by school library.
\end{abstract}

Keywords: Modes of reading. Vlogs. Mediation. School library.

Bibl. Esc. em R., Ribeirão Preto, v. 6, n. 1, p. 43-63, 2018.

DOI: 10.11606/issn.2238-5894.berev.2018.132613 


\section{Introdução}

O que norteia este artigo é a leitura em formato eletrônico, sendo destacadas as principais implicações dessa nova modalidade de leitura no comportamento dos usuários. Hoje a internet possibilita acessar diversos documentos em tempo hábil, ler uma informação que ainda nem foi publicada, produzir seus próprios textos ou vídeos e baixar gratuitamente arquivos que acabaram de ser lançados em outros países. A chegada da web 2.0 possibilitou a criação de blogues, redes sociais, sites de troca de conteúdo e buscadores, veículos de exploração do vasto ciberespaço.

A presença da informação no ciberespaço (mundo virtual) e a abundância de ferramentas para acessá-la fazem com que o virtual seja uma extensão do real. Acompanhando a crescente integração destes mundos, a indústria cultural começou a adicionar diversas mídias, concedendo aos seus produtos um caráter multimidiático. Desse modo, como explica Jenkins (2008), uma história que antes era contada exclusivamente em livros passa a atingir o cinema, os seriados de televisão, os mercados de quadrinhos e videogames, por exemplo.

Neste contexto de inovações tecnológicas e convergências midiáticas surgem os vlogs. O vlog é uma ferramenta da internet com conteúdo em formato de vídeo que vem ganhando espaço entre os jovens. Jovens entre 13 e 24 gastam cerca de 11,3 horas por semana assistindo vídeos na internet (PALERMINO), e a maior plataforma de hospedagem e compartilhamento de vídeos do mundo é o YouTube (MOLYNEAUX; O'DONNELL; GIBSON; SINGER, 2008).

Isso não significa que todo esse tempo é investido em $v \operatorname{logs}$, no entanto, considerando que as celebridades mais influentes entre adolescentes nos EUA são vlogueiros (ou vloggers, que são os autores de $v \log s$ ), mesmo concorrendo com atores de Hollywood (AULT, 2014), é razoável assumir que boa parte dele (tempo investido em vídeos) se concentra nos vlogs. Confirmando essa assunção, Nogueira (2015) relata que vlogueiros brasileiros possuem milhões de seguidores no YouTube, conquistados com uma conversa "de jovem para jovem". Portanto, pode-se afirmar que o público alvo dos vlogs é, em grande parte, constituído por adolescentes.

Com a popularidade dessa mídia em mente, fica evidente que ela tem potencial para se tornar uma ferramenta de incentivo à literatura. Por um lado, que foge do controle das 
instituições de ensino, vlogueiros famosos poderiam dedicar sua influência para disseminar conhecimento. Porém, por outro lado, alunos poderiam ser estimulados a compartilhar seu conhecimento em $v \log s$ pessoais ou organizados pela biblioteca escolar. Esse estímulo não teria como justificativa apenas o interesse dos jovens pela produção de vídeo, mas também o fato de eles serem "nativos digitais" e, portanto, possuirem certa naturalidade com tecnologias audiovisuais.

Os adolescentes da atualidade, por terem nascido já no século $\mathrm{XX}$, atendem aos critérios da definição de nativos digitais, de Prensky (2001). Ou seja, eles nasceram na era cibernética e não conseguem imaginar um mundo sem a convergência midiática e a internet. Seus modos de leitura são edificados sobre os suportes eletrônicos, não se resumindo, simplesmente, à absorção da informação, mas à interação direta com a fonte da informação, por meio de um comentário, de um sinal de aprovação ou de reprovação.

As facilidades oferecidas pela tecnologia eletrônica alteram os modos de leitura dos adolescentes, uma vez que os vlogs estão ocupando um espaço significativo dentre as mídias on-line disponíveis. Além disso, a internet está superando outros meios de comunicação, como a televisão, segundo estudo realizado em 2014 pela Interactive Advertising Bureau, em parceria com a ComScore, a internet já é a mídia mais consumida no país, sendo a mais importante para $80 \%$ dos pesquisados (IAB, 2014).

Este texto, de natureza predominantemente teórica e bibliográfica, apresenta um breve histórico e caracterização dos modos de leitura, do vlog, dos nativos digitais e da biblioteca escolar, tendo como objetivo explicar como o vlog pode ser uma poderosa ferramente de incentivo à leitura e apresentar propostas de como esse recurso pode ser explorado na biblioteca escolar.

\section{Modos de leitura e o advento de internet}

Na Antiguidade, segundo Manacorda (1998), a transmissão do conhecimento tinha como principal meio a oratória, com oradores autores cumprindo o papel de mestres e ouvintes leitores cumprindo o papel de aprendizes. O surgimento da escrita não alterou este cenário, pois o texto era reproduzido por um orador, chegando aos ouvidos do aprendiz como mensagem oral, conforme Manguel (1997) e Chartier e Cavallo (2002). 
A leitura "silenciosa" (ou mental) começou a ser praticada no século X, permitindo estudos mais eficientes e íntimos. No entanto, ela era vista com preconceito aos olhos de adeptos da leitura oral que a associavam à ociosidade, de acordo com Chartier (1998). Nos mosteiros, ademais, temia-se que o leitor, ao abandonar a oralidade, refletisse sobre o texto sem a devida orientação, chegando a conclusões supostamente equivocadas.

Apesar da resistência, a leitura mental ganhou força ao longo dos anos. Ela era a modalidade preferida nos scriptorium europeus, como demonstra Fischer (2005), e, eventualmente, se tornou a modalidade padrão para todos os eruditos da Europa Ocidental.

Mesmo com a crescente preferência pela leitura mental, a oralidade continuou presente na sociedade como importante modalidade de leitura. Considerando que, na Alta Idade Média, $5 \%$ da população urbana e $1 \%$ da população rural correspondiam ao número de pessoas letradas, fica evidente a relevância social da oralidade, visto que a informação poderia chegar aos não letrados somente sob a mediação de um orador (FISCHER, 2005).

Mais tarde, a Revolução Industrial, no final do século XVIII, foi um marco importante para a evolução dos modos de leitura, pois possibilitou a passagem da leitura intensiva para a leitura extensiva, como ressalta Darnton (1995). A leitura intensiva consistia na repetição de pequenos trechos textuais, geralmente bíblicos. Após a Revolução, obras informativas e de entretenimento começaram a ser produzidas em larga escala, o que aumentou a exposição dos leitores às publicações, dessacralizou a escrita e introduziu uma categoria de textos que não precisavam ser estudados.

Outro efeito da Revolução Industrial, como destaca Fischer (2005), foi a ampliação drástica no número de leitores. Além do aumento do número de publicações, os leitores eram estimulados pelo acréscimo nos índices de alfabetização e por inovações tecnológicas, como a iluminação a gás, por exemplo.

As noções conceituais contemporâneas de leitura surgiram nesta época, como esclarece Abreu (2003). Elas foram padronizadas em um nível tão profundo que as práticas anteriores parecem estranhas para um leitor do século XXI. Entretanto, o conceito de leitura transcende tais noções. Freire (1988) afirma que a leitura do mundo precede a leitura da palavra. Martins (1999) e Soares (2004) concordam que a leitura não se resume à decodificação de palavras, sendo possível ler os olhos, o mundo, o tempo ou, até mesmo, gestos. 
Após a Revolução Industrial, outro evento impactante para o desenvolvimento da leitura foi a chegada da internet. A mudança da página impressa para a tela do computador é comparada à repercussão da invenção da impressa, com Gutenberg. Autores como Bellei (2002), Lévy (2003), Koch e Elias (2010), bem como Marcushi e Xavier (2010), concordam que paradigmas socioculturais são abalados pela evolução dos modos de leitura. A internet deixou essa assertiva muito evidente, apresentando novos suportes e redefinições de conceitos como hipertexto, mediação, mídia, leitor e autor.

Os suportes que, de acordo com Chartier (2002), a revolução da informação introduziu foram, entre outros, o computador pessoal, o laptop, os telefones celulares, os tablets, os smartphones e os e-book readers. Diferentemente do livro, que possui elementos textuais estáticos, os novos suportes eletrônicos são altamente interativos, podendo, até mesmo, contar com animações e efeitos audiovisuais. Neste novo ambiente, a leitura tem como elemento essencial o hipertexto.

Hipertexto, segundo Lévy (1999), é um conjunto de nós ligados por conexões. Os nós podem ser palavras, imagens e gráficos, entre muitos outros elementos. Ao acessá-los, o leitor é levado a outro texto, que faz parte de uma rede de textos conectados por links. Em outras palavras, múltiplos textos são conectados por links, os quais são acionados por nós.

O hipertexto existia antes do advento da internet, manifestando-se em notas de rodapé, referências e índices remissivos, conforme relembram Marcushi e Xavier (2010). Porém, na dinâmica da internet, de acordo com Bellei (2002), a quebra do fluxo sequencial do texto é um fator intrínseco, pois o leitor, ao invés de seguir uma sequência preestabelecida, traça seu próprio trajeto pela rede.

Enquanto navega pela web, lendo fragmentos de textos em uma trajetória hipertextual, o leitor se aproxima do esquema mental de processamento de dados, como observa Ramal (2002). Outro resultado da revolução da informação foi a aproximação dos conceitos de autor e leitor. Nos novos suportes, como mencionam Chartier (1998) e Ghaziri (2008), o leitor pode interagir com o texto, publicando comentários, atualizando conteúdos e recortando trechos para serem usados em outro lugar.

Ademais, nunca foi tão fácil ser leitor, pois a leitura contemporânea, "atividade interativa altamente complexa de produção de sentido”, segundo Koch e Elias (2010, p. 11), integram texto, áudio, animações e muitos outros recursos que tornam o texto atraente. Por 
outro lado, nunca foi tão fácil ser autor, visto que todos são livres para publicar textos na internet. Sem as restrições do controle editorial e com o contato direto com os leitores, os quais podem influenciar o conteúdo do texto, o conceito de autoria está sofrendo transformações significantes. Neste sentido, Beiguelman (2003) explica que a soberania do autor é, ao mesmo tempo, diluída e multiplicada.

Os conceitos de leitor e autor ficam ainda confusos quando o trajeto individual do leitor pelo hipertexto é analisado. Corroborando para esta ideia, Rezende (2008) afirma que o leitor edita o texto que lê. A função atípica de autor fica forte com a análise da interpretação individual do leitor em relação ao hipertexto, a qual depende de sua leitura de mundo, que é ainda mais individual.

Retornando para a interação entre autor e leitor, é importante esclarecer que ela não ocorre apenas quando o autor publica seu texto na internet. Pelo contrário, pode ocorrer com qualquer tipo de texto. Histórias dos livros mais vendidos, por exemplo, podem instigar a criação de fã-clubes, a organização de eventos de cosplay, produção de artes idealizadas por fãs e, até mesmo, a publicação de fanfictions e vlogs.

Desse modo, fica evidente o contexto sócio-histórico e a materialidade do texto neste início de século XXI. O contexto é de autores-leitores que interagem com o conteúdo que leem em um suporte dinâmico. Tais são as transformações operadas sobre os modos de leitura pelo advento da internet.

\section{Transmídia, vlogs e nativos digitais}

A dimensão das obras transmidiáticas transcende um único texto. Elas são trabalhadas em diferentes mídias, sempre abrindo novas possibilidades para serem exploradas mais tarde. Seguindo este raciocínio, Scolari (2009) define o termo "narrativa transmidiática", como uma estrutura que se expande tanto em linguagens (verbais, icônicas e textuais) quanto em mídias (televisão, rádio, jogos e quadrinhos).

Exemplificando o conceito de transmídia, Jenkins (2007) menciona a franquia The Matrix, que conta uma história por meio de três filmes de longa-metragem, uma série de curtas animadas, duas coleções de histórias em quadrinhos e diversos jogos de videogame. 
Não há uma fonte única onde a experiência inteira está condensada. Assim, o leitor, ao consumir apenas um dos produtos da franquia, tem acesso a apenas uma parte da história.

É importante distinguir transmídia de multimídia. Uma narrativa em multimídia se aproveita de diversas plataformas para recontar sua história, enquanto uma narrativa em transmídia tem sua história fragmentada, ficando a cargo de cada mídia contar uma parte dela, tendo como objetivo ligar o público à informação, convergindo por meio de diversos meios em busca de mais trechos da história contada, ao acrescentar informações e mostrar partes do universo, com a finalidade de torná-lo mais convincente e compreensível.

A narrativa transmidiática só pode ser compreendida com o conceito de convergência em mente. Jenkins (2008) define convergência em três partes, consistindo no fluxo de conteúdo através de múltiplos suportes midiáticos, na cooperação entre diferentes indústrias midiáticas e no comportamento migratório de audiências midiáticas.

Enquanto o fluxo de conteúdo está diretamente relacionado com a já mencionada ideia de fragmentação da narrativa, a cooperação entre indústrias midiáticas consiste na estratégia comercial de direcionar conteúdo para determinada audiência em determinado suporte. Um exemplo dessa cooperação seria a articulação entre as indústrias literária e de quadrinhos infantis, para produzir um romance sobre Homem-Aranha que atinja o público feminino e quadrinhos para colorir que atinja o público infantil (JENKINS, 2007).

O comportamento migratório, enfim, consiste no movimento dos leitores, de uma plataforma para outra, caçando fragmentos da informação dispersa que permita a formação de uma imagem coerente do todo. $\mathrm{O}$ autor se apoia na ideia de inteligência coletiva para explicar como a dispersão da informação estimula a formação de comunidades de leitores que compartilham o que sabem para remontar a narrativa.

O número de diferentes mídias nas quais a narrativa pode se desenvolver é diretamente proporcional ao avanço da tecnologia. As séries televisivas, por exemplo, se tornaram uma possibilidade com a consolidação e o acesso à televisão no mercado de consumo. Mais tarde, o uso de websites para complementar uma história com informações adicionais pôde ser feito apenas com a popularização do computador. Portanto, novas tecnologias digitais originam novas mídias. 
O vlog é um exemplo destas novas mídias. Burgess e Green (2009) explicam que a palavra vlog é derivada da palavra blog, que é como são chamados os sites com postagem de textos e imagens relacionadas à vida pessoal do autor ou outros assuntos de sua preferência.

Segundo Burgess e Green (2009), os diários on-line, que antes eram basicamente textos e fotos, converteram-se para diários em vídeo, que, além de textos e fotos, permitem também áudio, trilha sonora, efeitos especiais e uma edição que se ajusta ao produto final. Outro atributo é que os vlogs, assim como os blogs, apresentam uma forma seriada, pois seguem uma sequência de fatos na vida do vlogueiro e o público acompanha a evolução como se acompanhasse temporadas de uma série ou novela.

O vlog foi galgando sua importância e se popularizando entre internautas de todas as idades, desde seu surgimento, no início do século XXI. Segundo Luna e Branco (2013), o vlog se popularizou no Brasil durante o ano de 2010 e teve sua difusão facilitada pelo YouTube, lançado em 2005, que oferecia um meio fácil e de qualidade para disseminar vídeos curtos. Burgess e Green (2009) explicam que os vlogs, como ocorrem com os blogs, se constroem com base na relação entre o autor e seus leitores. A estrutura dos vlogs incentiva os comentários, o compartilhamento de informações e a troca de conteúdos que não raro ocorre em tempo real, o que transforma o YouTube em uma grande rede social.

Os temas abordados, assim como nos blogs, vão desde assuntos de relevância social até trivialidades da vida cotidiana. As opiniões dos vlogueiros definem seu público-alvo e exercem significante influência sobre ele, ao longo das postagens periódicas que podem ser diárias, semanais ou de qualquer outro padrão temporal.

A faixa etária mais susceptível a tal influência, como fora mencionado na introdução, é a dos adolescentes. Segundo Outeiral (2003), a adolescência desperta com a puberdade, um período do desenvolvimento humano em que diversas mudanças psicobiológicas começam a ocorrer, como um acelerado crescimento físico, o amadurecimento das glândulas reprodutoras e o despertar sexual.

À medida que os fenômenos da puberdade acontecem ficam marcadas as diferenças específicas dos dois sexos, as quais mais tarde contribuem para distinção na formação da identidade definitiva. $\mathrm{Na}$ adolescência, alguns sinais ficam evidentes como o crescimento dos seios e a primeira menstruação nas meninas. Nos meninos há um aumento dos testículos e a primeira ejaculação (SIQUEIRA, 2003). 
Existem diferentes teorias que tentam definir o início e o fim deste período com diversos critérios, como as condições psíquicas e sociais, por exemplo. Com o duplo significado de "apto para crescer" e "apto para adoecer", o termo "adolescente" designa uma categoria de pessoas que se divide em três etapas, organizadas por idade: a adolescência inicial (entre 10 e 14 anos de idade), caracterizada pelas primeiras transformações corporais e psíquicas; a adolescência média (entre 14 e 17 anos de idade), caracterizada pela sexualidade; e a adolescência final (entre 17 e 20 anos de idade), caracterizada por novos vínculos parentais, pelo interesse profissional e pela entrada no mundo adulto (OUTEIRAL, 2003).

O ordenamento jurídico brasileiro adotou o critério objetivo para definir legalmente as fronteiras da adolescência: o adolescente é a pessoa entre doze e dezoito anos de idade, de acordo com o artigo $2^{\circ}$ do Estatuto da Criança e do Adolescente (BRASIL, 1990).

Conforme Aberastury e Knobel (2008) a adolescência é caracterizada por intenso crescimento, desenvolvimento e marcantes transformações anatômicas, quando o indivíduo busca a sua identidade adulta, tomando como ponto de apoio as primeiras relações afetivas vivenciadas, principalmente na família.

Outeiral (2003) concorda e acrescenta que a adolescência é um fenômeno psicossocial que acompanha a fase do crescimento marcada por grandes transformações corporais. O processo de transição do familiar corpo infantil e o desconhecido corpo adulto pode ocorrer sob três tipos de regimes psíquicos: o regime persecutório, caracterizado pela forte presença de ansiedades; o regime maníaco, caracterizado pela negação da dor causada pela transição; e o regime fóbico, caracterizado pela fuga da realidade. O regime psíquico por meio do qual o adolescente enfrenta as transformações corporais pode ser constatado através de desenhos, queixas, distúrbios psicológicos (como a anorexia e a bulimia), relações sociais e roupas.

Segundo Outeiral (2003), a palavra foi inaugurada no século XIX, pelo escritor francês Victor Hugo. Porém, a ideia de adolescência é ainda mais recente, datando do período entre a Primeira e a Segunda Guerras Mundiais. Antes disso, não havia período distinto de transição entre criança e adulto.

Dentre as inúmeras características dos adolescentes, é interessante destacar aquelas relacionadas à leitura. Filipouski (1995) diz que eles se encontram em um estágio do desenvolvimento das habilidades cognitivas no qual operações formais são dominadas. Isso significa que eles experimentam, pela primeira vez, um alto poder de abstração. Além disso, 
apresentam uma preferência para assuntos reais, sobre os quais podem elaborar juízos de valor, demonstrando pouco interesse pela fantasia.

Com o advento da internet e sua exploração de forma global, surgiu o ciberespaço, um espaço virtual onde as relações sociais são desenvolvidas pelo meio da tecnologia. Sendo palco de inúmeros fenômenos socioculturais, o ciberespaço ganhou uma legião de usuários que nele investe uma parte considerável de seu tempo. E a frequência regular de um ambiente virtual por pessoas do mundo inteiro originou uma nova cultura: a cibercultura. Esta é entendida como um conjunto de espaços, atitudes, rituais e costumes que as pessoas desenvolvem quando entram em contato com a tecnologia.

Foi nesse contexto que surgiram os nativos digitais, como serão chamados os adolescentes neste trabalho. O conceito abrange todo aquele que nasceu após a década de 80 , imerso na cibercultura desde o primeiro dia de vida. Enquanto as gerações anteriores precisaram se adaptar à era cibernética, passando por um processo de transição, os nativos digitais não conheceram o mundo sem o ciberespaço.

Os autores-leitores que protagonizam o processo de leitura anteriormente descrito são conhecidos como nativos digitais, conceito que designa todo aquele que nasceu depois dos anos 80 e se aproveita de todos os aparatos tecnológicos no seu cotidiano. Os nativos digitais são os maiores representantes de uma cultura própria da era cibernética: a cibercultura. Turkle (1997) explica que a cibercultura é a cultura da simulação, caracterizada por formas de pensamento não lineares.

Esta geração está acostumada a obter informações de forma rápida e costuma recorrer primeiramente a fontes digitais e à web antes de procurar em livros ou na mídia impressa. Como explica Tapscott (2010), os nativos digitais são capazes de realizar diversas tarefas ao mesmo tempo e têm facilidade com o uso das tecnologias digitais.

Os nativos digitais têm o costume de ficar conectados com seus pares, através de seus celulares e mensagens instantâneas SMS (os torpedos) ou computadores ligados à rede da internet e ferramentas de comunicação como Messenger (Skype), Google-Talk e outros (TAPSCOTT, 2010). Prensky (2001) afirma que esta geração pensa e processa informações de forma diferente e sua familiaridade com a linguagem digital faz com que ela seja para eles como uma segunda língua. 
Mattar (2010) descreve como peculiar a geração dos nativos digitais e afirma que a aprendizagem desses jovens acontece de forma interativa, baseada em suas descobertas. $\mathrm{O}$ que se quer dizer é que o nativo digital aprende fazendo. Como acrescenta Johnson (2005), uma criança desta geração compreende e se adapta rapidamente a uma tecnologia digital, fazendo uso de suas ferramentas sem precisar ler o manual de instrução. O cérebro dos nativos digitais se adapta com muito mais facilidade às inovações tecnológicas do que o dos seus pais, que, nos termos de Prensky (2001), são apenas imigrantes no mundo digital.

Tapscott (2010) e Prensky (2001) concordam e acrescentam que a diferença desta geração com as anteriores é o uso da tecnologia de informação e comunicação em tarefas rotineiras e habituais; conexão permanente com as mídias digitais; leitura nos monitores de maneira intensa; uso multifuncional dos recursos tecnológicos; polivalência na realização de tarefas em simultâneo; interações em rede; comunicação síncrona e aprendizagem experimental e lúdica, o que conjetura competência no emprego das ferramentas e serviços da web.

A cada nova geração de pessoas ocorre paralelamente uma nova geração de aparatos tecnológicos, num processo contínuo e irreversível, especialmente com fins para o uso doméstico, acarretando o uso cada vez mais precoce das tecnologias por parte das crianças, o que pode vir a determinar novas possibilidades de acesso, uso e interação.

A característica mais marcante dos jovens atuais é exatamente o fato de estarem completamente conectados, e hoje é possível aliar qualquer atividade a esse meio de comunicação. O vlog é uma dessas alternativas que possibilita que os indivíduos compartilhem e criem qualquer tipo de informação.

Nesse contexto, a biblioteca escolar precisa ajustar seus serviços e produtos às necessidades e comportamentos informacionais e acompanhar esta nova geração, pois é prestadora de serviços informacionais e responsável pelo desenvolvimento do usuário da informação, em suportes diversos e multimidiáticos.

O papel principal que a biblioteca escolar pode desempenhar no contexto sóciohistórico dos nativos digitais é o de mediadora da informação digital. Entende-se por informação digital tudo aquilo que é passível de ser armazenado ou transferido eletronicamente.

Almeida Júnior (2015, p. 25) define mediação da informação como: 
[...] toda ação de interferência - realizada em um processo, por um profissional da informação e na ambiência de equipamentos informacionais -, direta ou indireta; consciente ou inconsciente; singular ou plural; individual ou coletiva; visando a apropriação de informação que satisfaça, parcialmente e de maneira momentânea, uma necessidade informacional, gerando conflitos e novas necessidades informacionais.

Em outras palavras, por meio do processo de mediação, o profissional da informação explora um ambiente onde circulam inúmeras informações, seleciona aquelas capazes de atender as necessidades momentâneas do usuário e as prepara para serem apresentadas. A mediação da informação propõe que o fazer do profissional da informação deve estar integrado com a comunidade que atende com a finalidade de promover espaços de apropriação da informação.

\section{Biblioteca escolar e a aplicação do vlog}

A biblioteca escolar, para Corrêa et al. (2002), é a instituição na qual ítens bibliográficos e informações estão organizadas e disponibilizadas de tal maneira que seja instigado o interesse pela pesquisa, pela leitura, pela criatividade e pela consciência crítica.

Castro Filho e Romão (2011 p. 139) a definem como "espaço de confluência, imbricação, encontro e diálogo de várias vozes, manifestas em livros, revistas, jornais, quadrinhos, filmes, etc.”. Os autores complementam dizendo que ela "é, ainda, local de aprendizagem, leitura e fomento cultural".

Ademais, a biblioteca é empregada pela instituição de ensino como um recurso essencial para o processo educativo. Campello (2006) ressalta que a biblioteca escolar consegue representar o contexto informacional de uma sociedade, sendo, portanto, o lugar mais adequado para a criança aprender sobre o mundo que a cerca.

A função da biblioteca escolar é, essencialmente, educativa. Ela atua como um estímulo ao autodesenvolvimento do aluno e como um catalisador em sua formação como leitor. Nesse sentido, Fragoso (2002) explica que a biblioteca escolar é um reforço para a relação aluno e professor.

Além de reforço, ainda segundo Fragoso (2002), ela é uma instituição prestadora de serviços à comunidade escolar e efetivadora do planejamento curricular. Portanto, ela tem uma função político-pedagógica que se desdobra juntamente com a própria escola. 
Para Silva e Araújo (2014, p. 17) as bibliotecas escolares são: “[...] equipamentos fundamentais no processo de formação do leitor autônomo, crítico e reflexivo, além de contribuir no processo de ensino-aprendizagem, como apoio didático aos educadores e às pesquisas dos educandos".

Segundo o Manifesto IFLA/UNESCO a missão da biblioteca escolar é a de capacitar os estudantes para a aprendizagem e ampliar sua imaginação, preparando-os para viverem como cidadãos (IFLA, 2000). O Manifesto destaca, explicitamente, o papel da biblioteca escolar na preparação do usuário para a vida social e, implicitamente, na preparação para as vidas acadêmica e profissional. Essa preparação se dá por meio da exposição do usuário à informação e ao conhecimento contido tanto no acervo como nos demais serviços oferecidos.

A biblioteca escolar está inserida em uma instituição de ensino, com a finalidade essencial de atender as necessidades da comunidade escolar. A missão das bibliotecas escolares também é definida por Côrte e Bandeira (2011, p. 8) como “[...] um espaço de estudo e construção do conhecimento, coopera com a dinâmica da escola, desperta o interesse intelectual, favorece o enriquecimento cultural e incentiva a formação do hábito da leitura".

Segundo Furtado e Oliveira (2010), a biblioteca escolar é o ambiente ideal para o incentivo à prática da leitura e escrita literária, em grupo e comunidade virtuais, quer no espaço web ou no seu recinto. Trabalha, assim, com a imaginação coletiva, promovendo interesse mútuo e repertório compartilhado, tendo como instrumento a literatura.

Com o advento da web 2.0, a literatura infantojuvenil teve sua valorização incrementada. Isso ocorreu devido ao interesse do público-alvo no computador como suporte de leitura e na convergência de múltiplas linguagens, que conferiu aos textos maior dinamicidade e a possibilidade de se reproduzir em diversas mídias.

Chartier (2009) defende que, diante dessa situação, a escola e os meios de comunicação devem preservar o conceito de criação intelectual, que tende a ficar cada vez mais instável, e se certificar de que tanto o suporte digital quanto o papel estejam sendo valorizados. Considerando a função pedagógica da biblioteca escolar e sua vocação natural para lidar com assuntos relativos à leitura, é evidente que o dever defendido por Chartier automaticamente se estende a ela.

Nas comunidades on-line, o usuário participa ativamente na construção do material literário, editando seus próprios textos. Desse modo, a publicação na web pode ser usada para 
estimular crianças e adolescentes a escrever. Mesmo reconhecendo que há especificidade na leitura e escrita da internet, Amaral (2008) defende que pode haver mediação entre formalismo e comunicação em qualquer espaço, mesmo, no ciberespaço.

Com base nos argumentos apresentados, considera-se que as mudanças e inovações devem ser vistas como uma oportunidade de enriquecimento do papel da biblioteca escolar e incentivo para novos serviços e produtos, para fins de atração de seus usuários e presença no cotidiano de crianças e jovens.

Com base no que fora explicado anteriormente, fundamentado em Tapscott (2010), Prensky (2001), Mattar (2010) e Johnson (2005), fica evidente que para chamar a atenção dos nativos digitais é preciso apresentar conteúdo interativo, que possa ser recebido de maneira dinâmica e, rapidamente, utilizado em alguma atividade. A metodologia de ensino que cobra o contato do aluno com a obra literária, seja simplesmente para cumprir a ementa cobrando resenhas ou para promover discussões críticas e enriquecedoras, não tem o poder de cativar todos os alunos. Ela cativa apenas aqueles que se interessam por literatura. Isso ocorre não apenas pela falta de dinamicidade, mas também porque, conforme pesquisa com adolescentes do ensino secundário com o intuito de investigar os eventos de letramento de estudantes em dois espaços sociais: bibliotecas e escolas, tendo como hipótese que diferentes espaços sociais podem constituir diferentes letramentos (ZAPPONE; NASCIMENTO; MELLO, 2014), foi constatado que estudantes não gostam de ser obrigados a ler e escrever o que não querem.

Para resolver o problema da leitura obrigatória, pode-se, por exemplo, conceder liberdade aos alunos para escolherem o que será lido e, aos poucos, introduzir as obras que fazem parte da ementa. Trata-se de uma ideia simples de se conceptualizar, mas logisticamente complexa de se estruturar e implementar, assim como seriam outras possíveis soluções que enfrentassem o problema como está sendo formulado na presente pesquisa. Entretanto, há uma solução que, além de ser logisticamente simples, consequentemente resolve, também, o problema da dinamicidade: o vlog.

Como vem sendo defendido, o vlog é uma ferramenta que, não só altamente interativa (BURGESS; GREEN, 2009), mas também popular entre os adolescentes (NOGUEIRA, 2015). Ademais, estes ou já conhecem ou facilmente se adaptariam ao processo de produção de $v \log$, visto que, em conformidade com os conceitos de nativos e imigrantes digitais de Prensky (2001), seriam os educadores quem mais teria dificuldades em aprender a usar o recurso. 
A relação entre $v \log$ e literatura não é óbvia nem objeto de abundante produção acadêmica. A primeira pista de que os dois são conciliáveis é a existência da palavra chave "vlog literário". Na internet, esse termo de busca pode listar, como resultados, vlogs dedicados a discussões literárias ou vlogs que, na verdade, são adaptações de obras literárias. O primeiro resultado é congruente com o conceito de $v \log$ já apresentado, de "diário on-line", no qual o vlogueiro compartilha assuntos de seu interesse. Nesse caso, trata-se de interesse literário, capaz de atrair uma audiência que também gosta de literatura. De acordo com Cet (2016), esses vlogueiros são conhecidos como booktubers, apaixonados por literatura que fazem críticas literárias no YouTube.

O segundo resultado, por outro lado, é algo completamente diferente, pois trata de conteúdo que apenas se apresenta em forma de vlog, ou seja, que o usa como instrumento. As adaptações literárias em formato de vlog tem feito sucesso na web desde 2012, quando The Lizzie Bennet Diaries, uma adaptação da obra Orgulho e Preconceito de Jane Austen, foi lançado (WELSH, 2015). Luna e Branco (2013) afirmam que trazer o vlog para a sala de aula pode ser instrutivo e, ao mesmo tempo, divertido, servindo como entretenimento e envolvimento para os estudantes e seus colegas.

A proposta, portanto, de aplicação do vlog no ensino da literatura é de: (a) substituir as atividades de resumo ou resenha por gravações informais nas quais os alunos documentam suas experiências literárias; ou, (b), organizar a classe para realizar uma adaptação de determinada obra literária.

A proposta da adaptação é, na verdade, logisticamente complicada, ao contrário do argumento que justifica o emprego do vlog, porém é uma alternativa interessante e conta com projetos detalhados que podem ser consultados nos artigos Parâmetros para organizar uma oficina de vlog na biblioteca escolar, de Alves e Silva (2016), e $O$ vlog como gênero textual aplicado a questões de ensino de Literatura, de Luna e Branco (2013).

A proposta da documentação de experiências literárias é mais simples, exigindo apenas um instrumento de filmagem, como o telefone celular, e de um computador para publicar e compartilhar o vlog. Idealmente, os alunos teriam a opção de escolher a obra literária de seu interesse, para evitar o problema da obrigação e manter a atividade mais próxima da condição de "irreverente" possível, com o educador introduzindo obras da ementa estrategicamente. No entanto, espera-se que apenas o fato de os alunos terem algo fácil, 
rápido e divertido para fazer logo após terminarem de ler um capítulo, ou qualquer outra unidade de leitura definida pelo instrutor, já é suficiente para engajá-los.

Não obstante todas essas considerações sejam feitas com um professor de literatura em mente, a biblioteca escolar pode ser o estúdio onde o projeto é desenvolvido, desde sua gravação até sua publicação. A participação da biblioteca escolar nas atividades pedagógicas, a propósito, é um tema muito importante a ser discutido.

Segundo Silva (2009), mesmo existindo bibliotecas nas escolas ainda falta uma "convivência pedagógica entre a biblioteca e a escola", pois os alunos não estão acostumados a frequentarem este local, muito menos aproveitar seu acervo. $O$ autor defende que a biblioteca escolar só pode cumprir a sua função de integrar-se ao ensino numa escola se o mediador, professor e/ou bibliotecário for "um profissional dinâmico, pois caberá a ele estabelecer a ponte entre a biblioteca e os alunos, a biblioteca e os professores, e entre a biblioteca e os conteúdos". (SILVA, 2009, p. 133).

Furtado (2013) assinala que o primeiro passo para a introdução das tecnologias digitais nas escolas deve ser dado com a prática dos educadores, conhecendo e usando as ferramentas, plataformas e processos, pois a prática torna-se importante para percepção de valores e significados.

A participação dos educadores pode ser encorajada pelo contato via plataformas digitais, nas quais eles possam trocar experiências, disseminar boas práticas e compartilhar projetos exitosos, podendo ainda desencadear um trabalho em conjunto e on-line. Para Silva e Tenório (2014, p. 203), "é preciso que o educador da biblioteca se envolva com a comunidade escolar, estabelecendo parcerias com os professores, desenvolvendo propostas para formação do leitor e promoção da leitura e acesso à cultura".

O profissional da informação é um mediador que proporciona o elo entre o leitor e a informação, de forma significativa, o que corresponde dizer que ele oferece ao leitor a oportunidade de protagonista no contexto da informação, deixando esse indivíduo de ser apenas um espectador e passe a utilizar as informações para se tornar cidadão responsável pela sociedade na qual vive e garantir um futuro melhor para si mesmo.

\section{Conclusão}


Os modos de leitura têm se modificado ao longo da história. Atualmente, os leitores interagem com o conteúdo que leem em um suporte dinâmico, que é a internet, trilhando seu próprio caminho por meio dos hipertextos e influenciando os autores em publicações futuras através de seus comentários.

$\mathrm{Na}$ internet, a narrativa transmidiática é predominante, com informações trafegando por diversas mídias de tal maneira que uma relação de interdependência seja estabelecida entre elas. Entre as diversas mídias usadas no ciberespaço, destaca-se o vlog, aos quais produtores e webespectadores dedicam dezenas de horas todas as semanas. O vlog é um vídeo, ou uma série de vídeos, por meio do qual uma pessoa, real ou fictícia, compartilha assuntos de seu interesse com os usuários que a seguem.

Grande parte dos vlogueiros e, principalmente, de seus seguidores são "nativos digitais", ou seja, crianças e adolescentes que já nasceram imersos na cibercultura, "falando" com naturalidade o "idioma digital". Enquanto as pessoas que não nasceram conectadas ao ciberespaço, seja pela idade ou pelas condições socioeconômicas, precisam se adaptar às inovações tecnológicas, em um processo de transição, os nativos digitais não conhecem um mundo sem elas (PRENSKY, 2001).

Sendo assim, aproveitando o interesse dessa geração pelo vlog, espera-se que essa pesquisa possa estimular a biblioteca escolar a explorar o potencial dessa nova ferramenta tecnológica como instrumento de incentivo à literatura, aliada à equipe pedagógica, especialmente com os docentes de literatura.

\section{Referências}

ABERASTURY, A.; KNOBEL, M. Adolescência normal: um enfoque psicanalítico. Porto Alegre: Artmed, 2008.

ABREU, M. Os caminhos dos livros. Campinas: Mercado de Letras/ALB/FAPESP, 2003.

ALMEIDA JÚNIOR. O. F. Mediação da informação: um conceito atualizado. In:

BORTOLIN, S.; SANTOS NETO, J. A.; SILVA, R. J. (Org.) Mediação oral da informação e da leitura. Londrina: ABECIN, 2015. p. 9-29.

AMARAL, S. Internet: novos valores e novos comportamentos. In: SILVA, E. (Org.). A leitura nos oceanos da internet. 2.ed. São Paulo: Cortez, 2008. 126p. 
ALVES, R. P. S; SILVA, R. J. Parâmetros para organizar uma oficina de vlog na biblioteca escolar. In. SEMINÁRIO EM CIÊNCIA DA INFORMAÇÃO, 6, 2016, Londrina.

Anais...Londrina: SECIN, 2016. p. 530-542. Disponível em: <http://www.uel.br/eventos/cinf/index.php/secin2016/secin2016/paper/viewFile/262/146>. Acesso em 23 jun. 2017.

AULT, S. Survey: YouTube stars more popular than mainstream celebs among U.S. teens. 2014. Disponível em: <http://variety.com/2014/digital/news/survey-youtube-stars-morepopular-than-mainstream-celebs-among-u-s-teens-1201275245/>. Acesso em: 18 jun. 2017.

BRASIL. Lei 8.069, de 13 de julho de 1990. Dispõe sobre o Estatuto da Criança e do Adolescente e dá outras providências. Diário Oficial da União, seção I, p. 13563, 16 de julho de 1990.

BEIGUELMAN, G. O livro depois do livro. São Paulo: PETRÓPOLIS, 2003.

BELLEI, S. L. P. O livro, a literatura e o computador. São Paulo: EDUC, 2002.

BURGESS, J.; GREEN, J. YouTube e a revolução digital: como o maior fenômeno da cultura participativa está transformando a mídia e a sociedade. São Paulo: Aleph, 2009.

CAMPELLO, B. S. A escolarização da competência informacional. Revista Brasileira de Biblioteconomia e Documentação, São Paulo, v. 2, n. 2, p. 63-77, dez. 2006. Disponível em: <http://rbbd.febab.org.br/rbbd/article/view/18/6> . Acesso em: 28 nov. 2016.

CASTRO FILHO, C. M.; ROMÃO, L. M. S. Livros-ninhos e leitores-passarinhos: outros sentidos de documento. In: CRIPPA, G.; MOSTAFA, S. P. Ciência da Informação e Documentação. Campinas: Alínea, 2011.

CET, V. L. D. Booktubers: os canais literários e uma nova forma de conhecer literatura. 2016. Disponível em: <http://cartacampinas.com.br/2016/11/booktubers-os-canais-literariose-uma-nova-forma-de-conhecer-literatura/>. Acesso em: 24 jun. 2017.

CHARTIER, R. A aventura do livro: do leitor ao navegador. São Paulo: Unesp, 1998.

O desafio da escrita. São Paulo: Unesp, 2002.

Os livros resistirão às tecnologias digitais. Revista Nova Escola, 2009. Disponível em: 〈http://revistaescola.abril.com.br/edicoes/ pdf/0204/falamestre.pdf >. Acesso em: 20 jan. 2017.

CHARTIER, R.; CAVALLO, G. História da leitura no mundo ocidental. São Paulo: Ática, 2002. v. 2.

CORREA, E. C. D. et al. Bibliotecário escolar: um educador? Revista ACB:

Biblioteconomia em Santa Catarina, Florianópolis, v. 7, n. 1, p. 107-123, 2002. Disponível em: 〈http://www.brapci.ufpr.br/search_result.php>. Acesso em: 21 jun. 2016.

CORTE, A. R.; BANDEIRA, S. P. Biblioteca escolar. Brasília: Briquet de Lemos, 2011. 
DARNTON, R. O beijo de Lamourette: mídia, cultura e revolução. São Paulo: Companhia das Letras, 1995.

FILIPOUSKI, A. M. R. Leitura em crise na escola: as alternativas do professor. Porto Alegre: Mercado Aberto, 1995.

FISCHER, S. R. História da leitura. São Paulo: Unesp, 2005.

FRAGOSO, G. M. Biblioteca na escolar. Revista ACB: Biblioteconomia em Santa Catarina, Florianópolis, v. 7, n. 1/2, p. 124-131, jan./dez. 2002.

FREIRE, P. A importância do ato de ler: em três artigos que se completam. 22. ed. São Paulo: Cortez, 1988.

FURTADO, C. C. Biblioteca escolar, nova geração e tecnologias da informação e Comunicação. In: CONGRESSO BRASILEIRO DE BIBLIOTECONOMIA, DOCUMENTAÇÃO E CIÊNCIA DA INFORMAÇÃO, 25. Florianópolis, 2013. Anais... Florianópolis: CBBD, 2013. Disponível em: <http://portal.febab.org.br/anais/article/view/1244>. Acesso em: 10 jan. 2017.

FURTADO, C. C.; OLIVEIRA, L. A. Biblioteca escolar na formação de comunidades de leitores-autores via web. Informação \& Sociedade: Estudos, João Pessoa, v. 20, n. 1, p. 1323, jan./abr. 2010. Disponível em:

<http://www.ies.ufpb.br/ojs/index.php/ies/article/view/3868>. Acesso em: 18 jan. 2017.

GHAZIRI, S. M. Da leitura no impresso à leitura na tela: novas veredas para a formação do leitor na escola. 2008. 179f. Dissertação (Mestrado em Educação) - Faculdade de Filosofia e Ciências, Universidade Estadual Paulista, 2008. Disponível em:

<http://www.marilia.unesp.br/Home/PosGraduacao/Educacao/Dissertacoes/ghaziri_sm_ms mar.pdf>. Acesso em: 10 jun. 2016.

INTERACTIVE ADVERTISING BUREAU. [IAB]. maio 2014. Disponível em: <http://iabbrasil.net/artigos >. Acesso em: 15 maio 2016.

INTERNATIONAL FEDERATION LIBRARY ASSOCIATIONS AND INSTITUTIONS. [IFLA]. Manifesto IFLA/UNESCO para biblioteca escolar. Tradução Neusa Dias Macedo. São Paulo: IFLA, 2000. Disponível em: <http://www.ifla.org/files/assets/school-librariesresource-centers/publications/school-library-guidelines/school-library-guidelines-pt_br.pdf $>$. Acesso em: 15 maio 2016.

JENKINS, H. Cultura da convergência: a colisão entre os velhos e novos meios de comunicação. 2. ed. São Paulo: Aleph, 2008.

Transmedia storytelling 101. 2007. Disponível em:

$\langle$ http://henryjenkins.org/2007/03/transmedia_storytelling_101.html $>$. Acesso em: 23 jun. 2017.

JOHNSON, S. Surpreendente: a televisão e o videogame nos tornam mais inteligentes. Rio de Janeiro: Elsevier, 2005. 
Vlogs e o incentivo à formação de leitores

KOCH, I. V.; ELIAS, V. M. Ler e compreender: os sentidos do texto. 3. ed. São Paulo: Contexto, 2010.

LÈVY, P. Cibercultura. Rio de Janeiro: 34, 1999.

A inteligência coletiva: por uma antropologia do ciberespaço. 4. ed. São Paulo: Loyola, 2003.

LUNA, R. P; BRANCO, S. O. O vlog como gênero textual aplicado a questões de ensino de literatura. Revista Letras Raras, Campina Grande, 2013. Disponível em: <http://150.165.111.246/revistarepol/index.php/RLR/article/view/142/129>. Acesso em: 2 jan. 2017.

MANACORDA, M. A. História da educação: da antiguidade aos nossos dias. São Paulo: Cortez, 1998.

MANGUEL, A. Uma história da leitura. São Paulo: Companhia das Letras, 1997.

MARCUSCHI, L. A.; XAVIER, A. C. Hipertexto e gêneros digitais: novas formas de construção de sentido. São Paulo: Cortez, 2010.

MARTINS, M. H. O que é leitura. São Paulo: Brasiliense, 1999.

MATTAR, J. Games em educação: como os nativos digitais aprendem. São Paulo: Pearson Prentice Hall, 2010.

MOLYNEAUX, H.; O'DONNELL, S.; GIBSON, K.; SINGER, J. Exploring the gender divide on YouTube: an analysis of the creation and reception of vlogs. 2008. Disponível em: $<$ https://www.researchgate.net/profile/S_Odonnell/publication/44070600_Exploring the_Gen der_Divide_on_YouTube_An_Analysis_of the_Creation_and/links/02e7e5379f25dea942000 000.pdf>. Acesso em: 18 jun. 2017.

NOGUEIRA, R. Youtubers são formadores de opinião de jovens, mas que valores eles passam? 2015. Disponível em:

$<$ https://entretenimento.uol.com.br/noticias/redacao/2015/10/19/youtubers-sao-formadoresde-opiniao-de-jovens-mas-que-valores-eles-passam.htm>. Acesso em: 18 jun. 2017.

OUTEIRAL, J. Adolescer: estudos revisados sobre adolescência. Rio de Janeiro: Revinter, 2003.

PALERMINO, C. L. Millennials watch more YouTube than TV, study says. Disponível em: 〈https://www.digitaltrends.com/movies/youtube-millennials-tv/>. Acesso em: 23 jun. 2017.

PRENSKY, M. Digital natives, digital immigrants. Trad. Roberta de Moraes Jesus de Souza. On The Horizon, NCB University Press, v. 9, n. 5, p. 1-6, 2001. Disponível em: <http://poetadasmoreninhas.pbworks.com/w/file/fetch/60222961/Prensky\%20\%20Imigrantes\%20e\%20nativos\%20digitais.pdf>. Acesso em: 18 abr. 2017. 
RAMAL, A. C. Educação na cibercultura: hipertextualidade, leitura, escrita e aprendizagem. Porto Alegre: Artmed, 2002.

REZENDE, K. E. Leitura, comunicação e hipertexto. Revela Periódico de Divulgação Científica da FALS. [s.1], v. 2, n. 3, ago. 2008. Disponível em:

<http://www.fals.com.br/revela11/leitura.pdf > . Acesso em: 22 fev. 2017.

SCOLARI, C. A. Hipermediaciones: elementos para uma teoria de la comunicación digital interactiva. Barcelona: Gedisa, 2009. Disponível em:

$<$ http://www.casadellibro.com/libro-hipermediaciones-elementos-para-una-teoria-de-lacomunicacion-di-gital-interactiva/9788497842730/1223908>. Acesso em: 11 abr.2017.

SILVA, R. J. Biblioteca escolar: organização e funcionamento. In: SOUZA, R. J. (Org.). Biblioteca escolar e práticas educativas: o mediador em formação. Campinas: Mercado das Letras, 2009.

SILVA, R. J.; ARAÚJO, L. M. História das bibliotecas escolares em Londrina.

Informação@Profissões, Londrina, v. 3, n. 1/2, p. 01 - 20, jan./dez. 2014. Disponível em: $<$ http://www.uel.br/revistas/uel/index.php/infoprof/article/view/21008? >. Acesso em: 18 fev. 2017.

SILVA, R. J.; TENÓRIO, G. O. Biblioteca escolar e mediação de leitura: uma proposta de fichas pedagógicas de registro dos livros. Informação@Profissões, Londrina, v. 3, n. 1/2, p. 197-212, jan./dez. 2014. Disponível em:

<http://www.uel.br/revistas/informação $>$. Acesso em: 11 jan. 2017.

SIQUEIRA, M. T. M. Adolescência. Revista de Psicologia Brasil, São Paulo, v.1, n.1, p.1618, ago. 2003.

SOARES, M. Letramento e alfabetização: as muitas facetas. Revista Brasileira de

Educação, Universidade Federal de Minas Gerais, Centro de Alfabetização, Leitura e Escrita. Belo Horizonte. jan./abr. 2004. Disponível em:

<http://www.scielo.br/pdf/rbedu/n25/n25a01.pdf/>. Acesso em: 13 abr. 2017.

TAPSCOTT, D. A hora da geração digital: como os jovens que cresceram usando a internet estão mudando tudo, das empresas aos governos. Rio de Janeiro: Agir Negócios, 2010.

TURKLE, S. A vida no ecrã: a identidade na era da Internet. Lisboa: Relógio D’água, 1997.

WELSH, K. The best vlog reinventions of classic books. 2015. Disponível em:

$<$ https://www.theguardian.com/books/booksblog/2015/jan/12/vlog-classic-novels-zoella-janeausten>. Acesso em: 24 jun. 2017.

ZAPPONE, M. H. Y.; NASCIMENTO, S. B.; MELLO, A. C. A. A leitura ficcional feita por adolescentes: compassos e descompassos entre escola e vida social. Raído, Dourados, v. 8, n. 17, jul./dez. 2014. Disponível em:

<http://ojs.ufgd.edu.br/ojs/index.php/Raido/article/view/3479>. Acesso em 24 jun. 2017. 